\title{
Value of Serum Neopterin Level in Evaluating Ulcerative Colitis Disease Activity
}

\author{
Hoda Abd-Elaziz El-Hady ${ }^{1}$, Sahar A. El-Nemr ${ }^{2}$, Hanan Samir Ahmed ${ }^{3}$ \\ Departments of Internal Medicine ${ }^{1}$, Tropical Medicine ${ }^{2}$ and Clinical Pathology, \\ Faculty of Medicine, Zagazig University,Egypt.
}

Corresponding Author Sahar A El-Nemr

Mobile:

$+201007246450$

\section{E}

mail:alnimrsahar@ya hoo.com

Key words: Ulcerative (U.C.) colitis Neopterin
Background and study aim: Ulcerative colitis (UC) is a major type of inflammatory bowel disease (IBD). It is characterized by chronic inflammation of the large bowel occurring in genetically susceptible individuals exposed to environmental factors and typically, has a relapsingremitting pattern. Neopterin serves as a marker of cellular immune system activation. This study aims to evaluate serum neopterin concentration as being a new biomarker for U.C. disease activity evaluation and to correlate it with some of the other markers of disease activity.

Patients and methods: This study included 80 subjects, twenty apparently healthy volunteers as a control group (Group I) that included (13 male and 7 female, mean age \pm SD $36.0 \pm 12.6 \mathrm{y})$ and sixty patients with UC disease as a patient group (Group II) that included (46 male and14 female, Mean age \pm SD $35.5 \pm 9.6$ y) Group II was subdevided into 20 patients recently diagnosed as active U.C. disease, 20 patients clinically in relapse and 20 patients clinically in remission. Colonoscope and calculation of Simple Ulcerative Colitis Clinical Activity Index Score (SCCAIS) was done for patients with U.C. Laboratory investigations as complete blood count (CBC), erythrocytic sedimentation rate (ESR), Complete liver and kidney function tests, Prothrombin time (PT), partial thromboplastin (PTT), International Normalizing Ratio (INR)

\section{INTRODUCTION}

Ulcerative Colitis (U.C.) is a chronic idiopathic inflammatory bowel disease (IBD) that differentiates itself by exhibition of a nontransmural, continuous and symmetrical pattern of inflammation limited to the colon with distal to proximal extension in disease progression. U.C. follows a and determination of serum neopterin level were done for all subjects.

Results: Serum neopterin level for the U.C. patients was (Mean $\pm \mathrm{SD}=18.6 \pm 5.79$, range $=6-40$ ) which is highly significant than the control subjects with ( Mean \pm $\mathrm{SD}=5.9 \pm 2.4$, Range $=2.7-9.8)$. Serum neopterin concentration was positively correlated with SCCAIS ( $r=0.77$ and Pvalue $<0.001$ ) that indicates a high significant relation between serum neopterin level and clinical active U.C. than in those whose disease was in clinical remission. Serum neopterin concentration was positively correlated with ESR, TLC, platelet count and PT $(\mathrm{r}=0.71, \mathrm{P}$-value $<0.001), \quad(\mathrm{r}=$ 0.41 , P-value $<0.001)$, $(\mathrm{r}=0.34, \mathrm{P}$-value $<0.01)(\mathrm{r}=0.28$, P-value $<0.05)$ respectively, whereas negatively correlated with $\mathrm{Hb}$. $(\mathrm{r}=-0.56$, P-value $=<0.001)$ and albumin $(\mathrm{r}=$ -0.35 , P-value $<0.01)$. There was statistically a high significant relation between serum neopterin level and endoscopic disease distribution (P-value <0.001) as serum neopterin level increases with the increasing of the U.C. disease extent.

Conclusions and Recommendations: Serum neopterin concentration can be used as a new biomarker for U.C. activity that could reliably distinguish between clinically active and inactive U.C., as well as, it can be a helpful tool in predicting the stage of the disease activity. Moreover, the degree of elevation in serum neopterin concentration may be in part related to location and extent of disease.

chronic course, punctuated by clinical remissions and relapses [1].

Typically macroscopic lesions are mucosal ulcerations, with immune cell infiltration and cryptic abscesses at histology. U.C. usually manifests with bloody diarrhea, is associated with a number of extra-intestinal manifestations and may be acutely complicated by toxic megacolon [2]. 
Diagnosis of U.C. is based on clinical symptoms combined with radiological and endoscopic investigations [3]. Endoscopy remains an invasive, time-consuming, and expensive procedure. Hence, colonoscopy could not be reasonably repeated in the setting of a regular follow-up. Clinical indices are indirect and often inaccurate predictors of endoscopic activity [4].

The need for a diagnostic tool that would improve the conventional methods in IBD diagnosis directed the search towards potential immunological markers, since an aberrant immune response against microbial or endogenous antigens in a genetically susceptible host seems to be implicated in IBD pathogenesis [5].

Neopterin, a stable pteridine derivative, is synthesised by macrophages upon stimulation with the pro-inflammatory cytokine and Interferon-gamma (IFN- $\gamma$ ) through induced transcriptional activation of the rate-limiting enzyme of pteridines biosynthesis (Oxenkrug et al., 2011). Neopterine is indicative of a proinflammatory immune status. It serves as a marker of cellular immune system activation $[6,7]$.

This study aims to evaluate serum neopterin concentration as being a new biomarker for U.C. disease activity evaluation and to correlate it with some of the other markers of disease activity.

\section{SUBJECTS AND METHODS}

This case-control study was carried out in Internal and Tropical Medicine departments in collaboration with Clinical Pathology Department, Zagazig University Hospitals in the period from June 2014 to December 2015.

\section{Subjects:}

This study included 80 subjects. An informed consent was obtained from all individuals who shared in this study.

\section{Subjects were classified into 2 groups: Control group (group I):}

This group included twenty apparently healthy volunteers (13 male representing $65.0 \%, 7$ female representing 35.0\%, Mean age \pm SD 36.0 \pm 12.6 y, age Range $19-60$ y ).

\section{Patients group (group II):}

This group comprised sixty patients (46 male representing $76.7 \%$, 14 female representing 23.3 $\%$, Mean age \pm SD $35.5 \pm 9.6 \mathrm{y}$, age Range 1952 y) with U.C. disease. They were recruited from patients attending the Internal Medicine and Tropical Endoscopy Units and the IBD Outpatient Clinic of Zagazig University Hospitals. This group was further subclassified into three subgroups :

- Subgroup IIa : comprised 20 patients recently diagnosed as active U.C. disease.

- Subgroup IIb: comprised 20 patients clinically in relapse.

- Subgroup IIIc: comprised 20 patients clinically in remission.

\section{Inclusion criteria:}

- Age more than 18 years of both sexes.

- All patients with ulcerative colitis disease either recently discovered or previously discovered (i.e. ongoing remission and relapse).

\section{Exclusion criteria:}

- Age $<18$ years.

- Patients refused to enter the study.

- Patients with other active autoimmune disorder (unrelated to IBD).

- Patients with cancer (current or past).

- Patients with apparent viral infection or any other septic focus.

- Patients on specific medications affecting the inflammatory response (i.e. NSAID, interferon, etc...).

- Patients with renal impairment.

- In addition for the control subjects, individuals with a known history of or first-degree relative with IBD were excluded.

\section{Methods}

All patients with U.C.were subjected to the following :

1- Full history.

2- Complete physical examination.

3- Abdominal ultrasound: Using GE LogiQ P5 Japan instrument.

4- Calculating the Simple Ulcerative Colitis Clinical Activity Index Score (SCCAIS) devised by Walmsley et al. [8]; U.C. was considered active if the (SCCAIS) was $\geq 5$. Significant improvement in U.C disease activity is considered if there is a decrease of $>1.5$ points in the SCCAI (Table 1). 
Table ( 1 ): Components of the SCCAI [8]

\begin{tabular}{|l|c|}
\hline \multicolumn{1}{|c|}{ Symptom } & Score \\
\hline Bowel frequency (day) & 0 \\
\hline $1-3$ & 1 \\
\hline $4-6$ & 2 \\
\hline $7-9$ & 3 \\
\hline$>9$ & \\
\hline Bowel frequency (night) & 1 \\
\hline $1-3$ & 2 \\
\hline $4-6$ & \\
\hline Urgency of defecation & 1 \\
\hline Hurry & 2 \\
\hline Immediately & 3 \\
\hline Incontinence & 1 \\
\hline Blood in stool & 2 \\
\hline Trace & 3 \\
\hline Occasionally frank & \\
\hline Usually frank & 0 \\
\hline General well being & 1 \\
\hline Very well & 2 \\
\hline Slightly below par & 3 \\
\hline Poor & 4 \\
\hline Very poor & 1 per manifestation \\
\hline Terrible & \\
\hline $\begin{array}{l}\text { Extracolonic features } \\
\text { Arthritis, Uveitis, Erythema nodosuma } \\
\text { gangrenosum }\end{array}$ & \\
\hline & \\
\hline & \\
\hline & \\
\hline
\end{tabular}

5- Colonoscope was done for patients, it was performed with a Pentax EC 3440F colonoscope after bowel preparation for an adequate exam and to decrease the risk for potential complications [9].

It was done as follow :

a. Discontinue iron-containing medications or constipating agents.

b. Stop free diets for 24 hours.

c. Beginning approximately 18 hours prior to the exam, 4L of specially balanced electrolyte lavage solution (e.g., polyethylene glycol electrolyte [PEG]) U.S. given orally. Administer at a rate of 1 to $2 \mathrm{~L}$ per hour $(8 \mathrm{oz}$ every 10 minutes). Sugars should not be added to the gut lavage because this may cause sodium retention or lead to production of potentially explosive gases.

6- Laboratory investigations including :

- Complete blood count (CBC) by automated Celldyne 1700 machine.
- Erythrocytic sedimentation rate (ESR) by manual technique.

- Complete liver and kidney function tests by fully automated Chemistry Analyser (Mindray BS 800).

- Prothrombin time (PT), partial thromboplastin (PTT), International Normalizing Ratio (INR) were measured by an automated TECO analyser using Diamed chemicals.

7- Special investigations

- Quantitative determination of serum neopterin by ELISA technique: using neopterin ELISA kit REF59321; (ImmunoBiological Laboratories, Hamburg, Germany. 2014). Neopterin concentration was expressed as nanomol per liter $(\mathrm{nmol} / \mathrm{L})$.

- Serum neopterin less than $10 \mathrm{nmol} / \mathrm{L}$ is considered normal and high if it is more than $10 \mathrm{nmol} / \mathrm{L}$.

\section{Statistical Analysis}

All data were entered and analyzed using EpiInfo version 6 and SPSS version 8 for Windows. 


\section{RESULTS}

Table (2) Demographic data of the studied groups

\begin{tabular}{|c|c|c|c|c|c|c|}
\hline & \multicolumn{2}{|c|}{$\begin{array}{c}\text { Controls (groupI) } \\
\text { Number }=20\end{array}$} & \multicolumn{2}{|c|}{$\begin{array}{c}\text { Cases (groupII) } \\
\text { Number }=60\end{array}$} & $\mathbf{t}$ & P-value \\
\hline $\begin{array}{l}\text { Age (years) } \\
\quad \text { Mean } \pm \text { SD } \\
\text { Range }\end{array}$ & \multicolumn{2}{|c|}{$\begin{array}{c}36.0 \pm 12.6 \\
19-60\end{array}$} & \multicolumn{2}{|c|}{$\begin{array}{c}35.5 \pm 9.6 \\
19-52\end{array}$} & 0.21 & $\begin{array}{l}0.83 \\
\text { (NS) }\end{array}$ \\
\hline Gender & Number & $\%$ & Number & $\%$ & $\mathbf{X}^{2}$ & P-value \\
\hline $\begin{array}{l}\text { Male } \\
\text { Female }\end{array}$ & $\begin{array}{c}13 \\
7 \\
\end{array}$ & $\begin{array}{l}65.0 \% \\
35.0 \%\end{array}$ & $\begin{array}{l}46 \\
14 \\
\end{array}$ & $\begin{array}{r}\% 76.7 \\
23.3 \%\end{array}$ & 1.05 & $\begin{array}{c}0.3 \\
\text { (NS) }\end{array}$ \\
\hline
\end{tabular}

Table (3): Serum neopterin level among the studied groups

\begin{tabular}{|l|c|c|c|c|}
\hline \multicolumn{1}{|c|}{ Serum neopterin level } & $\begin{array}{c}\text { Group I } \\
\text { (Controls) }\end{array}$ & $\begin{array}{c}\text { Group II } \\
\text { (Cases) }\end{array}$ & t & P-value \\
\hline Mean \pm SD & $5.9 \pm 2.4$ & $18.6 \pm 5.79$ & 9.5 & $<\mathbf{0 . 0 0 1 * *}$ \\
Range (nmol/L) & $2.7-9.8$ & $6-40$ & & HS \\
\hline
\end{tabular}

There was statistically a high significant difference of serum neopterin among the studied groups (Pvalue $<0.001)$.

Table (4): Some clinical data and laboratory investigation of group II

\begin{tabular}{|c|c|c|c|c|}
\hline \multicolumn{2}{|c|}{ Clinical data } & Mean \pm SD & Range & Normal value \\
\hline \multicolumn{2}{|c|}{ SCCAIS } & $8.7 \pm 3.3$ & $3-16$ & Active $\geq 5$ \\
\hline \multirow{4}{*}{ 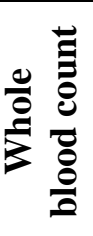 } & TLC & $11.6 \pm 4.4$ & $4.2-21.7$ & $\left(4-11 \times 10^{3} / \mathrm{uL}\right)$ \\
\hline & Hb. conc. & $12.0 \pm 1.3$ & $8.5-15$ & $(12-16 \mathrm{~g} / \mathrm{dl})$ \\
\hline & Hct. \% & $35.9 \pm 3.95$ & $25.2-44.5$ & $(37-47 \%)$ \\
\hline & Platelet count & $300.0 \pm 96.4$ & $158-585$ & $\left(150-400 \times 10^{3} / \mathrm{uL}\right)$ \\
\hline \multicolumn{2}{|c|}{ Serum Albumin } & $3.6 \pm 0.2$ & $3-4$ & $(3.5-5.3 \mathrm{~g} / \mathrm{dl})$ \\
\hline \multicolumn{2}{|c|}{ Serum Creatinine } & $0.9 \pm 0.19$ & $0.6-1.6$ & $(0.6-1.2 \mathrm{mg} / \mathrm{dl})$ \\
\hline \multirow{3}{*}{ 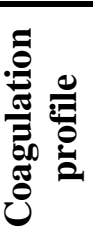 } & PT (second) & $12.7 \pm 0.5$ & $12-13.5$ & (11- 14 sec.) \\
\hline & $\overline{P T T}$ & $33.6 \pm 1.75$ & $30-39$ & (26- $42 \mathrm{sec})$. \\
\hline & INR & $1.13 \pm 0.04$ & $1.07-1.2$ & $(0.8-1.2)$ \\
\hline \multicolumn{2}{|r|}{ E.S.R. } & $45.3 \pm 22.4$ & $5-80$ & $(2-7 \mathrm{~mm} / \mathrm{h})$ \\
\hline
\end{tabular}

TLC: Total leucocytic count Hb: Hemoglobin Hct; Heamatocrit PT: Prothrombin time

PTT: Partial thromboplastine INR: International Normalizing Ratio E.S.R: Etythrocytic sedimentation rate. 
Table (5): Relation between serum neopterin level and different subgroups of group II patients

\begin{tabular}{|c|c|c|c|}
\hline \multirow{2}{*}{ Clinical activity } & \multicolumn{2}{|c|}{ Serum neopterin level } & \multirow{2}{*}{ Significance } \\
\cline { 2 - 3 } & Mean \pm SD & Range (nmol/L) & \multirow{2}{*}{$* * * \mathrm{HS}$} \\
\hline $\begin{array}{c}\text { Subgroup IIa } \\
\text { (Recently diagnosed) }\end{array}$ & $22.97 \pm 5.8$ & $17.6-40$ & $* * \mathrm{HS}$ \\
\hline $\begin{array}{c}\text { Subgroup IIb } \\
\text { (Relapse) }\end{array}$ & $19.7 \pm 3.1$ & $17.5-28$ & $* \mathrm{HS}$ \\
\hline $\begin{array}{c}\text { Subgroup IIc } \\
\text { (remission) }\end{array}$ & $13.2 \pm 3.0$ & $6.0-17.3$ & \\
\hline
\end{tabular}

$\mathrm{F}=28.2$

P-value $<0.001^{* *}$

Table (6): Least Significance Difference (LSD) of serum neopterin level in different subgroups of group II patients

\begin{tabular}{|c|c|c|c|}
\hline Group II subgroups & $\begin{array}{c}\text { Subgroup IIa } \\
\text { Recently diagnosed }\end{array}$ & $\begin{array}{c}\text { Subgroup IIb } \\
\text { Relapse }\end{array}$ & $\begin{array}{c}\text { Subgroup IIc } \\
\text { Remission }\end{array}$ \\
\hline $\begin{array}{c}\text { Subgroup IIa } \\
\text { (Recently diagnosed) }\end{array}$ & & $\begin{array}{c}\text { P-value }<0.05 \\
\mathbf{S}\end{array}$ & $\begin{array}{c}\text { P-value }<0.001 \\
\text { HS }\end{array}$ \\
\hline $\begin{array}{c}\begin{array}{c}\text { Subgroup IIb } \\
\text { (Relapse) }\end{array} \\
\end{array}$ & $\begin{array}{c}\text { P-value }<0.05 \\
\mathbf{S} \\
\end{array}$ & & $\begin{array}{c}\text { P-value }<0.001 \\
\text { HS } \\
\end{array}$ \\
\hline $\begin{array}{l}\text { Subgroup IIc } \\
\text { (Remission) }\end{array}$ & $\begin{array}{c}\text { P-value }<0.001 \\
\text { HS }\end{array}$ & $\begin{array}{c}\text { P-value }<0.001 \\
\text { HS }\end{array}$ & \\
\hline
\end{tabular}

Table (7): Correlation between serum neopterin level and other parameters in group II

\begin{tabular}{|c|c|c|c|c|}
\hline \multicolumn{2}{|c|}{ Parameters } & $\mathbf{r}$ & P-value & Significance \\
\hline \multicolumn{2}{|r|}{ Age } & -0.15 & $>0.05$ & $\mathrm{NS}$ \\
\hline \multicolumn{2}{|c|}{ SCCAIS } & 0.77 & $<0.001 * *$ & $\mathrm{HS}$ \\
\hline \multirow{4}{*}{ 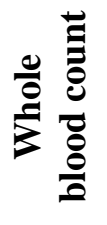 } & TLC & 0.41 & $<0.001 * *$ & HS \\
\hline & Hb. conc. & -0.56 & $<0.001 * *$ & HS \\
\hline & Hct. \% & -0.56 & $<0.001 * *$ & $\mathrm{HS}$ \\
\hline & Platelet count & 0.34 & $<0.01 *$ & HS \\
\hline \multicolumn{2}{|c|}{ Serum Albumin } & -0.35 & $<0.01^{*}$ & $\mathrm{HS}$ \\
\hline \multicolumn{2}{|c|}{ Serum Creatinine } & 0.12 & $>0.05$ & $\mathrm{NS}$ \\
\hline \multirow{3}{*}{ ن } & PT & 0.28 & $<0.05^{*}$ & $S$ \\
\hline & PTT & 0.04 & $>0.05$ & NS \\
\hline & INR & 0.26 & $>0.05$ & NS \\
\hline \multicolumn{2}{|c|}{ E.S.R. } & 0.71 & $<0.001 * *$ & $\mathrm{HS}$ \\
\hline
\end{tabular}


Table (8): Endoscopic disease distribution among the different subgroups of group II patients

\begin{tabular}{|c|c|c|}
\hline Group II subgroups & \multicolumn{2}{|c|}{ Endoscopic disease distribution } \\
\cline { 2 - 3 } & Pancolitis & Left colitis \\
\hline $\begin{array}{c}\text { Subgroup IIa } \\
\text { (Recently diagnosed) }\end{array}$ & 18 & 2 \\
\hline $\begin{array}{c}\text { Subgroup IIb } \\
\text { (Relapse) }\end{array}$ & 16 & 4 \\
\hline $\begin{array}{c}\text { Subgroup IIc } \\
\text { (Remission) }\end{array}$ & 12 & 14 \\
\hline Total number of cases & 46 & $23.3 \%$ \\
\hline$\%$ & $76.7 \%$ & \\
\hline
\end{tabular}

For subgroup IIc (Remission), the endoscope was done with the onset of diagnosis

Table (9): Relation between serum neopterin level and endoscopic disease distribution

\begin{tabular}{|c|c|c|c|}
\hline $\begin{array}{c}\text { Endoscopic disease } \\
\text { distribution }\end{array}$ & \multicolumn{2}{|c|}{ Serum neopterin level } & \multirow{2}{*}{ Significance } \\
\cline { 2 - 3 } & Mean \pm SD & Range $(\mathbf{n m o l} / \mathbf{L})$ & \\
\hline Pan colitis & $19.6 \pm 5.4$ & $10-40$ & $* * \mathrm{HS}$ \\
\hline Left colitis & $15.3 \pm 5.9$ & $6-29$ & $* \mathrm{HS}$ \\
\hline
\end{tabular}

$\mathrm{t}=2.52$

P-value $=0.012^{*}$

\section{DISCUSSION}

Ulcerative Colitis is a major type of IBD. Typically, it has a relapsing-remitting pattern. Diagnosis of U.C. is based on clinical symptoms combined with radiological and endoscopic investigations [10].

Endoscopy is accurate but is an invasive and expensive tool to follow up U.C. Hence, there has been a strong need to search for new biological markers of disease activity, which are simple to use in clinical practice, reliable and inexpensive. Hemoglobin, platelet count and ESR have been used for assessment of disease activity singly or in combination [11].

This study included eighty subjects (twenty apparently healthy volunteers and sixty patients with U.C. [20 patients recently diagnosed as active U.C. disease, 20 patient's clinically in relapse and 20 patients clinically in remission]).

In this study, elevated ESR, decreased (Hb. level \& Hct.\%) and decreased serum albumin were correlating with disease activity, also there were trends toward an elevated TLC, platelet count, and PT being markers of disease activity. So, these markers may be helpful as indicators for disease activity.

The results of the laboratory tests is in concordance with Sachar and Walfish [12] as they had mentioned that laboratory tests should be done to screen for anemia, hypoalbuminemia, and electrolyte abnormalities in U.C. patients. Liver function tests should be done. Other possible laboratory abnormalities include leukocytosis, thrombocytosis, and elevated acute-phase reactants (eg, ESR).

The number of white blood cells increases during the acute phase response and is also influenced by the drugs utilized in IBD, such as glucocorticoids (increased) or azathioprine and 6-mercaptopurine (decreased). Albumin is a negative acute phase marker and decreased levels may be found during inflammation [13].

Eng and Surawicz [14] had mentioned that laboratory evaluation may be helpful, but is never diagnostic. For example, an elevated white blood cell count can be seen with either acute self-limiting colitis or IBD. Anaemia, especially iron deficiency anaemia, suggests IBD, as the usual course in acute self-limiting colitis is too short for significant blood loss.

Also, Danese and Fiocchi [15] had mentioned that laboratory measurements are not diagnostic, but are helpful in assessing and monitoring disease activity and in differentiating U.C. from other forms of colitis. Blood counts and measurements of the ESR and the level of fecal lactoferrin or calprotectin help to determine the severity of the inflammation. 
Regarding SCCAIS we can found that it is a predictive of U.C. disease activity, but are never diagnostic. This is in concordance with Higgins et al. [16] as they had mentioned that the SCCAI is the most vigorously validated index in U.C. and has good psychometric and performance validity. The SCCAI is also an adequate replacement for more objective disease activity measurements such as endoscopy and blood tests. The clinician-based SCCAI is able to categorize two types of patients: patients with inactive U.C. disease (SCCAI score <5) and patients with active U.C. disease (SCCAI score $\geq 5$ ). These assessments require completion by the treating clinician, which makes them prone to bias, since the clinician gives an interpretation of the patient's response.So, this index gives an idea only about U.C. disease activity but not useful to detect the degree of the disease activity [17].

Ciećko-Michalska et al. [18] have reported that measurement of neopterin concentration in serum may be a useful marker to assess disease activity in patients with IBD. They observed a positive correlation between increased concentrations of neopterin in serum and increased levels of (TNF- $\alpha$ and CRP), increasing the number of (leukocytes and platelets count) and the degree of disease activity in patients with both U.C. and Chron's disease (C.D).

In this study, we found that serum neopterin concentrations for all of the participating control subjects were within the normal value. In comparison to the control group (I), all of the three subgroups of group II U.C. patients interpret higher serum neopterin concentrations, which are above the normal value.

Results in this study found that serum neopterin concentration is greater in patients with active U.C. disease and also increases in pancolitis. As shown in our results serum neopterin level is greater in U.C. patients whose disease affecting the whole colon than those patients with the disease limited to left colon. The previous observation suggests that the serum neopterin level is directly proportional to the extent of the inflammed part of the colon. However, a larger study would be needed to confirm those observations.

Moreover, serum neopterin concentration was significantly greater in patients with clinically active U.C. than in those whose disease was in clinical remission and so; their results are going with the results of Husain et al. [19].

\section{CONCLUSIONS}

- Serum neopterin concentration is increased in patients with clinically active U.C. when compared with controls, and therefore represents a new biomarker for disease activity that could reliably distinguish between clinically active and inactive ulcerative colitis

- The degree of elevation in serum neopterin concentration can be used as a helpful tool in predicting the stage of the disease activity. It may be in part related to location and extent of disease.

- Laboratory tests should be done to screen for anemia, hypoalbuminemia, electrolyte abnormalities, and other possible laboratory abnormalities as leukocytosis, thrombocytosis, and elevated acute-phase reactants (eg, ESR). These markers may be helpful as predictors for disease activity and severity, but are never diagnostic.

Ethical approval: Approved.

Funding: None.

Conflict of interest: Authors declare no conflict of interest related to this article.

\section{REFERENCES}

1- Lunney PC, Leong RWL. Review article: ulcerative colitis, smoking and nicotine therapy. Alimentary Pharmacology and Therapeutics 2012; 36(11-12): 997-1008.

2- Di Sabatino A, Biancheri P, Rovedatti L, Macdonald TT, Corazza GR. Recent advances in understanding ulcerative colitis. Internal and Emergency Medicine 2012; 7(2):103-111.

3- Wolf DC, Abraham BP, Afzali A, Allegretti PD, Arai R. Community Perspectives: Combining Serology, Genetics, and Inflammation Markers for the Diagnosis of IBD and Differentiation Between CD and UC. Gastroenterol Hepatol 2012 (N Y); 8(6 Suppl. 2): 1-16.

4- Masoodi I, Kochhar R, Dutta U, Vaishnavi C, Prasad KK, Vaiphei K et al. Fecal lactoferrin, myeloperoxidase and serum C-reactive are effective biomarkers in the assessment of disease activity and severity in patients with idiopathic ulcerative colitis. Journal of Gastroenterology and Hepatology 2009; 24(11): 1768-1774.

5- Kuna AT. Serological markers of inflammatory bowel disease. Biochem Med. (Zagreb) 2013; 23(1): 28-42. 
6- Murr C, Widner B, Wirleitner B, Fuchs D. Neopterin as a marker for immune system activation. Current Drug Metabolism 2002; 3(2): 175-187.

7- Geisler S, Gostner JM , Becker K. Immune activation and inflammation increase the plasma phenylalanine-to-tyrosine ratio. Fuchs D. (Editor-in-Chief). Pteridines2013; 24(1): 27-31, ISSN (Online) 2195-4720, ISSN (Print) 0933-4807.

8- Walmsley RS, Ayres RC, Pounder RE, Allan RN. A simple clinical colitis activity index. Gut 1998; 43(1): 29-32.

9- Scott-Conner CEH., Safadi BY , Marks J.M.: Diagnostic Colonoscopy (Part II; Chapter VII: page, 723). The SAGES Manual Fundamentals of Laparoscopy, Thoracoscopy and GI Endoscopy;2006, Scott-Conner C.E.H. (editor). 2nd Edition. ISBN: 13: 978-038723267-6. Published by Springer Science \&Business.

10- Nikolaus S, Schreiber S. Reviews in Basic and Clinical Gastroentrology: Diagnostics of Inflammatory Bowel Disease. Journal of Gastroentrology 2007; 133(5): 1670-1689. ElDiery W. and Metz D. (section editors.).

11- Desai D., Faubion WA. ,Sandborn WJ. Biomarkers in Inflammatory Bowel Disease. Aliment Pharmacol Ther 2006; 25(3), 247-255.

12- Sachar DB., Walfish AE. Diagnosis of IBD (Chapter: 19). The Inflammatory Bowel Disease: Gastrointestinal Disorders(section; 2: 166-175).The Merck Manual of Diagnosis and Therapy 2011; the $19^{\text {th }}$ edition. (Porter R.S., Kaplan J.L., Albert R.K., et al., editors). Published by Merck Sharp \& Dohme Corp., 2011. ISBN: 978-0-911910-19-3.

13- Cioffi M, Rosa AD, Serao R, Picone I, Vietri MT. Laboratory markers in ulcerative colitis: Current insights and future advances. World $J$ Gastrointest Pathophysiol 2015; 6(1): 13-22.
14- Eng SC , Surawicz CM. Differential diagnosis of colitis (Section II: The bedside, chapter: 21, Pages: 431-456). Inflammatory Bowel Disease: From Bench to Bedside Book, $2^{\text {nd }}$ Edition, 2005. Targan S.R., Shanahan F. and Karp L.C. (editors). ISBN (Online): 9780-387-25808-9. Published by Kluwer Academic Publishers.

15- Danese S, Fiocchi C. Review Article: Ulcerative Colitis. N Engl J Med 2011; 365(18): 1713-25.

16- Higgins PD, Leung J, Schwartz M, Mapili J, Wren PA, Zimmermann EM. The quantitative validation of non-endoscopic disease activity indices in ulcerative colitis. Aliment Pharmacology \& Theraputics 2006; 25:333342.

17- Bennebroek Evertsz' F, Nieuwkerk PT, Stokkers PC, Ponsioen CY, Bockting CL, Sanderman R, et al. The Patient Simple Clinical Colitis Activity Index (P-SCCAI) can detect ulcerative colitis (UC) disease activity in remission: A comparison of the P-SCCAI with clinicianbased SCCAI and biological markers. Journal of Crohn's and Colitis 2013;7: 890-900.

18- Ciećko-Michalska I., Fedak D. , Mach T. Neopterin in assessing the activity of inflammatory bowel diseases: ulcerative colitis and Crohn's disease, Przegl Lek. 2010; 67(12): 1262-5. PMID: 21591350.

19- Husain N, Tokoro K, Popov JM, Naides SJ, Kwasny MJ, Buchman AL. Neopterin concentration as an index of disease activity in Crohn's disease and ulcerative colitis. J Clin Gastroenterol 2013; 47(3): 246-251.

Peer reviewer: Walid Abdel-Dayem , Professor of Tropical Medicine and Hepatogastroenterology, Faculty of Medicine, Zagazig University, Egypt. Editor: Tarik Zaher, Professor of Tropical Medicine and Hepatogastroenterology, Faculty of Medicine, Zagazig University, Egypt 